\title{
Slam: poesia e performance de resistência
}

\author{
Lovani Volmer* \\ Suzana da Silva Souza** \\ Daniel Conte***
}

\section{Resumo}

Este trabalho busca evidenciar como o Slam propicia um novo espaço de produção e partilha poética, podendo abrir caminhos para descobertas no âmbito da autoafirmação e do reconhecimento a respeito das múltiplas lutas pela conquista de espaço, elevando vozes historicamente relegadas às coxias da vida social. Apresenta um olhar analítico dialógico e polifônico, além do entendimento de performance de Paul Zumthor; e apresenta o caso de Natália Pagot, slammer que se destaca pelo seus fazeres poéticos e performáticos. O trabalho aponta, ainda, a ideia de partilha do sensível de Jacques Rancière, a partir da qual defende a ideia de liberdade das condições imaginárias, a fim de que as gerações futuras possam conhecer uma nova forma de sociedade em que mulheres e homens, crianças, idosos e jovens, com suas etnias e sexualidades, tenham seus direitos validados e preservados com equidade e dignidade.

Palavras-chave: Slam. Vozes. Performance. Polifonia.

\section{Introdução}

Nas atividades da vida cotidiana, utilizamos diferentes linguagens que são inerentes à vida em sociedade. Aliando-se à literatura, a língua se revela e desenha os modos de determinada realidade, de determinado tempo e a literatura evidencia o idioma como bem comum de uma população e, mais especificamente, de acordo com Eco (2011), mantém a língua como patrimônio coletivo, embora ela defina seu próprio rumo com modificações estruturais, mostrando-se sensível às sugestões da literatura.

\footnotetext{
* Doutorado em Letras pela Universidade de Caxias do Sul/Uniritter, Brasil (2015). Professor da Universidade Feevale, Brasil. E-mail: lovaniv@feevale.br

** Mestre em Letras, pela Universidade Feevale. Tem graduação em Letras, com habilitação em Língua Portuguesa e respectivas literaturas pelas Faculdades Integradas de Taquara - Faccat. E-mail: suzanasouza@ sou.faccat.br

*** Doutorado em Literatura Brasileira, Portuguesa e Luso-africana pela Universidade Federal do Rio Grande do Sul, Brasil (2008). Professor Adjunto da Universidade Feevale, Brasil. E-mail: danielconte@feevale.br
}

Data de submissão: 09 dez. 2019 - Data de aceite: 04 mar. 2020 http://dx.doi.org/10.5335/rdes.v16i1.10348 
Compreendendo a literatura como necessidade indissociável ao desenvolvimento do indivíduo, entendemos também que ela é, consoante Candido (2004), um direito de todo ser humano. $\mathrm{O}$ autor esclarece-nos uma importante finalidade da literatura ao afirmar que ela coexiste nas dimensões individual e coletiva do ser humano, pois visa culminar em uma situação de comunicação entre indivíduos e seu tempo. Cabe, então, refletirmos a respeito das consequências da privação imposta pela violência simbólica, sobre determinados indivíduos, em relação às situações de comunicação propiciadas pelo pensamento que se torna expressão e, por conseguinte, pela literatura.

Como resposta a essa deliberada exclusão, surgem, na contemporaneidade, movimentos sociais e artísticos que visam descortinar as múltiplas formas de violência simbólica, responsáveis pela distinção entre aqueles que têm direito à educação, à literatura, às artes e os que são impedidos e silenciados à margem desses campos simbólicos. As bandeiras de liberdade e resistência a essas violências semânticas do imaginário social, conceituadas aqui como formas de legitimar e naturalizar as desigualdades sociais, estão cada vez mais articulando-se em movimentos como o Slam, por exemplo, para travar batalhas contra o sistema canônico (no que diz respeito à arte literária) e dominante (concernente à estrutura da sociedade), no intuito de inserir vozes, há muito caladas, no processo de autoria nos domínios literários e políticos.

Ao debruçarmo-nos sobre os estudos do Slam, cuja dinâmica muito se assemelha à empregada nas batalhas de rap, também popularizadas no Brasil, encontramos o modo como as batalhas propiciam um novo espaço de produção e partilha poética, podendo abrir caminhos para descobertas no âmbito da autoafirmação e do reconhecimento a respeito das múltiplas lutas pela conquista de espaço. Essas lutas foram iniciadas no passado, mas precisam ser ressignificadas no presente, a fim de que as gerações futuras possam conhecer uma nova forma de sociedade em que mulheres e homens, crianças, idosos e jovens, com suas etnias e sexualidades, tenham seus direitos validados e preservados com equidade e dignidade.

Nesse sentido, corroborando Compagnon (1999), consideramos o texto literário arte da linguagem e buscamos, neste estudo, elucidar de que maneira a dimensão artística e social do Slam viabiliza, pela poesia, o protagonismo e a reverberação das vozes marginalizadas na contemporaneidade.

\section{A tessitura poética}

A poesia é um tipo de materialização do gênero lírico. Entretanto, é preciso elucidar os motivos e o modo como foi institucionalizado o referido gênero e como tal instituição influenciou nos estudos 
de teoria literária no âmbito da poesia. Nesse sentido,

A teoria dos gêneros é um princípio de ordem: ela classifica a literatura e a história literária não por tempo ou lugar (período ou língua nacional) mas por meio de tipos de organização ou estrutura especificamente literários (WELLEK; WARREN, 2003, p. 307).

A referida organização é necessária para compreendermos a intencionalidade e o efeito temporal do texto poético, bem como a constituição da voz nele contida. Isso porque o gênero lírico possui características muito específicas quanto à sua construção e organização. Embora tenha sofrido alterações com o passar do tempo, certos elementos permanecem, de modo que a essência do gênero lírico ainda seja de fácil percepção. Esses elementos são a presença do eu-lírico e a relação íntima entre o sujeito que se expressa e o objeto perseguido por ele na constituição do texto poético. A respeito desse eu e das características do gênero lírico, entendemos que é

[...] indiscutível a afetividade e a emotividade do clima lírico, sempre ligado ao íntimo e ao sentimento, tornando fluida e inconsistente a relação entre o sujeito e o objeto, isto é, entre o eu e o mundo. A emoção e o sentimento impedem a configuração mais nítida das coisas e dos seres que não se fixam, mas fluem sem contornos definidos na torrente poética (CUNHA, 1979, p. 98).

É, em essência, a fluidez dos poemas que faz com que o interlocutor possa dele se apropriar na medida em que a subjetividade alcança o objeto da tessitura poética. Mediante a subjetividade, ocorre a partilha da sensibilidade dos temas propostos no fazer poético, o que explica a dimensão não aplicável à vida pragmática antes alegada.

Além da subjetividade que floresce no gênero lírico, outras características permeiam sua constituição com igual importância, a exemplo da presença de musicalidade, elemento oriundo da poética grega e atestado pela poesia trovadoresca medieval (CUNHA, 1979). A musicalidade é obtida a partir da utilização de vários mecanismos linguísticos e estilísticos, como o processo de aliteração e a elaboração de rimas.

$\mathrm{Na}$ contemporaneidade, entretanto, a musicalidade dos poemas relaciona-se, ainda, ao ritmo, cada vez mais acelerado, da vida humana, com todos os seus compromissos inerentes. Em outras palavras, toda

[...] atividade humana se desenvolve dentro de certo ritmo. Nosso coração pulsa alternando batidas e pausas; nossa respiração, nossa gesticulação, nossos movimentos são ritmados. Há trabalhos coletivos - no campo como na indústria - que têm rendimento maior em função do ritmo conjunto de todos os participantes. Certas provas esportivas em equipe dependem do ritmo conjunto para o bom resultado final. $O$ ritmo aparece também na produção artística do homem. De um modo especial, na poesia. Como o ritmo faz parte da ida de qualquer pessoa, sua presença no tecido do poema pode ser facilmente percebida por um leitor atento, que é, ao mesmo tempo, um ouvinte (GOLDSTEIN, 2005, p. 7).

Com efeito, a partir do ritmo dos fatos, do trabalho, dos afetos e da vida, a expressão poética na atualidade busca 
meios de conquistar seu lugar, abordando com criticidade tanto o cosmos individual, por meio da subjetividade, quanto o coletivo, com manifestações de oralidades performáticas e rítmicas que problematizam a estrutura social vigente.

De encontro às características elencadas, não podemos cair no engodo de que é possível depreender racionalmente 0 eu lírico e seu objeto por meio delas. A esse respeito, precisamos levar em conta o aspecto ilógico da criação poética, isto é, o não compromisso com a realidade, tal como a conhecemos no mundo, embora, com ela possa haver correspondência. A linguagem empregada no gênero lírico e, especialmente, na poesia, possui tópicos que se relacionam com a realidade do mundo e algumas conexões entre a poesia e a realidade são o próprio poeta e o sistema escrito ou imagístico. Ao se combinarem tais aspectos, nasce a poesia, e ela torna-se capaz de transcender à sua geração, de abarcar outros discursos; discursos anônimos, como depreendemos a partir da afirmação de que
A linguagem poética organiza, comprime os recursos da linguagem cotidiana e, às vezes, até comete violência contra ela, em uma tentativa de forçar a nossa consciência e atenção. Muitos desses recursos um escritor encontrará formados, ou pré-formados, pelas atividades silenciosas e anônimas de muitas gerações (WELLEK; WARREN, 2003, p. 17).
São, em suma, os métodos próprios, os subterfúgios do estilo e os recursos linguísticos que fazem do gênero lírico $o$ mais complexo no que tange à interpre-

tação, pois, embora estabeleça conexão com o mundo real, é concebido no onirismo e expresso pela voz de um eu que flutua entre os dois universos. Esse mesmo eu flutuante entre dois espaços distintos se constitui no lirismo da Poesia Marginal, mais especificamente, na função social do poeta, que, no período de maior difusão dessa poesia, se encontrava em uma realidade de extrema censura, mas, contra a corrente moralista, continuava produzindo e disseminando sua obra transgressora e denunciativa.

\section{Poesia marginal e Slam: uma poética do discurso}

O nascimento do que hoje conhecemos como Poesia Marginal ocorreu junto a outros eventos importantes no país, na segunda metade do século XX. O conceito foi usado inicialmente por teóricos da literatura no período do Tropicalismo, na década de 1960 e, de acordo com Mattoso (1981), junto ao movimento Tropicália, as tendências musicais romperam as barreiras que delimitavam os estilos aplaudidos e produzidos pelas mais variadas faixas etárias. Isso fez com que os jovens se sentissem atraídos por aquilo que era ou que pudesse ser considerado poesia, justamente quando, por meio do AI- $5^{1}$, a censura recaía sobre a efervescência artística e sobre os jovens. Como consequência, começavam a surgir poetas furtivos, que logo se tornaram 
conhecidos como marginais. A palavra (marginal) não raro gera confusão ao ser utilizada indiscriminadamente, pois

[...] sozinha não explica muito. Veio emprestada das ciências sociais, onde era apenas um termo técnico para especificar o indivíduo que vive entre duas culturas em conflito, ou que, tendo-se libertado de uma cultura, não se integrou de todo em outra, ficando à margem das duas (MATTOSO, 1981, p. 7-8).

Nesse sentido, a obra e os poetas expoentes desse estilo, de acordo com Mattoso (1981), contaram com outra alcunha bastante conhecida: a Geração Mimeógrafo. Tal título surgiu a partir do modo de impressão das obras produzidas por poetas cujas condições financeiras não permitiam que fossem impressas por editoras ou com acabamento mais rebuscado. Os escritores, portanto, mimeografavam amadoramente seus poemas engajados e críticos, e o mimeógrafo passou a ser, dessa maneira, equipamento indispensável ao ato de disseminar a poesia subversiva em conteúdo e forma.

Poetas marginais, sua poesia clandestina e o mimeógrafo tornaram-se para o público leitor dessas obras os porta-vozes da contestação e, consequentemente, da contracultura à qual estava relacionado o Tropicalismo e todos os movimentos menores, como a criação de pasquins, contra a ditadura. Tanto o equipamento quanto o modo de impressão do material simbolizaram a chave para o reconhecimento do contingente literário produzido por tal geração e
Prova disso é que após o destaque obtido pela poesia desses autores, especialmente em antologias e em estudos críticos, a maioria relançou muitos de seus livros, antes mimeografados, em grandes editoras. Ingressaram, assim, no campo literário brasileiro. Na verdade, utilizaram de uma inserção marginal para caminhar para o centro do sistema literário. Dificilmente os livros mimeografados por aquela geração gerariam efeitos no campo literário caso não tivessem sido inseridos em antologias e posteriormente acolhidos por críticos, jornalistas e professores universitários e publicados por grandes editoras (BRITTO, 2012, p. 125).

Ainda que a proposição de estudos e aprofundamentos acerca da obra dos poetas marginais só tenham sido possíveis a partir da validação de valor dessa poesia por parte da crítica literária e da academia, destacamos que uma das grandes contribuições desse movimento é essencialmente a ousada ideia de que qualquer pessoa, mesmo nas mais precárias condições, pode produzir poesia, desde que a sensibilidade do ser se transponha à ideia de comercialização da literatura.

Mimeografar poemas e jornais significava a demarcação de um território propositalmente marginal, tal como as várias pautas dos poetas desse estilo, conforme descreve Mattoso (1981):

O mimeógrafo sempre foi marginal em relação aos esquemas de produção e consumo, os poetas pornográficos sempre estiveram à margem da moral oficial, os poetas politizados sempre estiveram à margem do poder político [...], e tudo isso sempre foi, de uma forma ou de outra, marginal em relação ao quadro cultural como um todo, ou seja, um ‘tipo' de marginalidade não exclui necessariamente os outros (p. 30). 
A ideia, preconizada nas décadas de 1960 e 1970, de que qualquer pessoa é capaz de produzir poesia, independentemente das condições de impressão, podem, atualmente, ser depreendidas na expansão do Slam, por meio da divulgação do trabalho dos slammers. No mesmo caminho contestatório, o conteúdo da poesia marginal se assemelha ao conteúdo denunciativo dos poemas compartilhados nas batalhas de Slam, isto é, o slammer brasileiro carrega a história da poesia marginal ressignificada em outros temas e problemáticas.

Devido à facilidade de compartilhamento em tempo real e com um número de pessoas bem mais expressivo, a arte dos poetas que batalham nas edições chega cada vez mais longe em cada vez menos tempo. É nesse aspecto que as redes sociais e as plataformas audiovisuais estão sendo o maior diferencial comparado ao modo de divulgação da poesia marginal do século XX. O conteúdo dos poemas ainda é marginal em relação aos discursos das classes dominantes, mas a divulgação desse conteúdo está no centro da interação virtual, seja no Facebook, em páginas oficiais dos slammers; no Youtube, em canais oficiais dos eventos de Slam ou no Instagram, onde encontramos fotos e vídeos dos eventos ocorridos.

Em contraponto, não é sensato ignorarmos a imersão da sociedade, sobretudo a atual, nos parâmetros do sistema capitalista, que, desde muito tempo, envolve a produção e a expansão do que é considerado literatura. Conforme explicita-nos Lajolo (1982), existe, na sociedade moderna, uma espécie de trajeto comercial por onde a obra literária deve circular antes de cumprir sua natureza social. Desse ângulo, a literatura iguala-se a qualquer outro produto produzido e consumido, dentro dos moldes capitalistas.

Desse modo, o texto literário, especificamente, o poético, passa a exercer, também, função de resistência discursiva, pois é segregado da vida pragmática das pessoas e dos discursos cotidianos, ou seja, vai contra aquilo que visa se relacionar com os moldes capitalistas de produção literária, sendo o menor alcance ao público o preço dessa resistência. De modo mais detalhado,

A poesia há muito que não consegue integrar-se, feliz, nos discursos correntes da sociedade. Daí vêm as saídas difíceis: o símbolo fechado, o canto oposto à língua da tribo, antes brado ou sussurro que discurso pleno, a palavra-esgar, a autodesarticulação, o silêncio [...]. Essas formas estranhas pelas quais o poético sobrevive em um meio hostil ou surdo, não constituem o ser da poesia, mas apenas o seu modo historicamente possível de existir no interior do processo capitalista (BOSI, 1977, p. 142).

Nessa ótica, os estudos para compreender como e a partir de quais discursos são constituídos os cercos de resistência do gênero poético focalizam duas importantes características da poesia marginal: polifonia e dialogismo. De acordo com Roman (1993), valendo-se 
de elementos da teoria bakthiniana, a polifonia é, essencialmente, a presença de múltiplas vozes proferindo textos diferentes e polêmicos que advêm e, ao mesmo tempo, são geradores de novos discursos. O conceito de polifonia aplica-se também a textos literários, sejam eles escritos ou provenientes da tradição oral.

A presença da polifonia desvela-se, consoante Bakhtin (1981), à medida em que ela funciona como a refração do outro, a partir do qual a ideia inicial é refratada e torna-se passível de modificações em seu trajeto de recepção. Em outras palavras, como nos mostra Bezerra (2006, p. 271), a noção de que há um “ouvinte' e um 'entendedor' (parceiros do 'falante', do 'fluxo único da fala', etc.)" é substituída pela premissa de que as vozes das pessoas e, nesse caso, as vozes dos poetas expressas pelo eu lírico, são instrumentos de debate, discussão, ideias distintas e que essas vozes manifestam seu posicionamento no mundo por meio do dialogismo, o campo da linguagem. Dessa maneira, entendemos que

Toda a extensão da fala viva, do enunciado vivo é de natureza ativamente responsiva (embora o grau desse ativismo seja bastante diverso); toda compreensão é prenhe de resposta, e nessa ou naquela forma a gera obrigatoriamente: o ouvinte se torna falante (BEZERRA, 2006, p. 271).

Em decorrência de tal explicação, entendemos que a produção poética que carrega as múltiplas bandeiras de resistência cultural é plural e, portanto, dialógica e polifônica. Sobre essa questão, Machado (2005), relaciona à polifonia um dos conceitos-chave de Bakhtin, a cronotopia, e destaca que as obras estão situadas em um grande tempo, posto que são capazes de romper com limites do presente em que nascem. Referem-se tanto ao passado quanto ao futuro, ao devir.

$\mathrm{O}$ mesmo fenômeno ocorre com a produção poética que se constitui (em arte e linguagem; forma e conteúdo) engajada com as bandeiras sociais, como poesia crítica das slammers negras, que visam abrir caminhos para a própria enunciação frente ao patriarcalismo e ao racismo estrutural existentes na história do Brasil. A poesia dessas slammers reativa a historicidade de outras mulheres negras, escravizadas ou que viveram os efeitos do regime escravocrata, e que, no passado, não puderam se enunciar.

No contexto polifônico, desataca-se, ainda, o fato de que as vozes permanecem independentes e, destarte, compõem uma unidade de ordem superior à da homofonia, que prevê a ordenação das vozes proferindo discursos alinhados em suas ideologias e, consoante Roman (1993, p. 210), "subordinadas à harmonia que garante a unidade".

À guisa de complementação dos aspectos que ligam a polifonia ao universo lírico, salientamos a subjetivação dos efeitos expansivos da poesia, que ocorrem por meio da ressonância e da repercussão do poema. Mais detalhadamente, 
As ressonâncias se dispersam nos diferentes planos da nossa vida no mundo, a repercussão nos chama a um aprofundamento de nossa própria existência. Na ressonância, ouvimos o poema, na repercussão nós o falamos, pois é nosso. A repercussão opera uma revirada do ser. Parece que o ser do poeta é nosso ser. A multiplicidade das ressonâncias sai então da unidade do ser da repercussão. Dito de maneira mais simples, trata-se de uma impressão bem conhecida por todo leitor apaixonado por poemas: o poema nos prende por completo (BACHELARD, 1989, p. 187).

A partir da ideia expressa pelo autor, fica claro que a palavra e, portanto, também o poema, são dotados de uma carga que suscita no leitor e no ouvinte ressonâncias ideológicas que podem repercutir no interior de quem é afetado de alguma forma pelo poema e, assim, continuar gerando ressonâncias.

Ao vislumbrarmos o Slam sob a ótica polifônica, depreendemos que este é, em essência, um movimento sociocultural no qual os poemas, as diferentes vozes dos slammers e do público encontram o cronotopo $^{2}$ para fazerem reverberar seus múltiplos discursos, por meio da partilha de poemas e lutas. Nesse sentido, ao concebermos o Slam como palco para que as vozes à margem se manifestem, consideramos que ele também seja um importante lugar de fala que rompe com o silenciamento forçado dessas vozes. Nesse espaço,

[...] a partilha democrática do sensível faz do trabalhador um ser duplo. Ela tira o artesão do "seu" lugar, o espaço doméstico do trabalho, e lhe dá o "tempo" de estar no espaço das discussões públicas e da identidade do cidadão deliberante (RANCIÈRE, 2005, p. 65).
No palco do Slam, o sujeito exerce também o seu poder de voz, de cidadão atuante e deliberante, posto que, poeticamente, põe em evidência, na sua performance, os tópicos que julga pertinentes e carentes de serem abordados por outro viés. Com base nas proposições pautadas pelas reflexões de Djamila Ribeiro (2017) e de Jacques Rancière (2005), compreendemos que o lugar de fala ocupado pelo slammer é, por natureza, um espaço difuso. Isso porque é, ao mesmo tempo, transitório (precisa estar em espaços diferentes a cada edição) e partilhado (outros slammers ocupam esse lugar para apresentar a performance competidora). Além de partilhar o palco das suas narrativas com outros mais, tem de amparar o espaço comum, aquele que é a resistência e a rachadura nos discursos oficiais; a ficcionalização e a ressignificação da realidade; o seu espaço político de enunciação no mundo e o mundo onde partilha a sensibilidade.

\section{Slam: poesia e performance}

A dinâmica das batalhas de poesia do Slam muito se assemelha à empregada nas batalhas de rap, também popularizadas no Brasil. Entretanto, a influência oral sobre a musical e a maior flexibilidade para a leitura ou declamação são as principais diferenças. Nas batalhas de poesia, é possível que os poemas sejam lidos a partir de algum suporte impres- 
so ou virtual e não ocorre a preferência por textos inéditos ou construídos no momento de recitá-los.

Essa organização, apesar de mais moderna, no que diz respeito ao tipo de suporte para leitura ou à não obrigatoriedade da criação simultânea, ainda tece relação com as cantigas trovadorescas, uma vez que as de escárnio e maldizer expressam, dentre outros temas, críticas sociais. Assim,

A sátira trovadoresca é reconhecida por apresentar uma leitura social. O objetivo dos trovadores era satirizar os tipos sociais, em detrimento de características psicológicas e afins. Eram alvos das cantigas de escárnio, por exemplo, os membros do clero que eram conhecidos pela sovinice ou incompetência, e da mesma forma os nobres falidos e os abastados que judiavam dos pobres (ESTEVES; MENDES, 2011, p. 4).

O caráter crítico, que denunciava injustiças e privilégios permaneceu, porque também permaneceram as injustiças e os privilégios na contemporaneidade. Com base nessa ideia, percebemos a criticidade do conteúdo, como a mais evidente relação entre as raízes europeias das Cantigas Trovadorescas e as batalhas de rap e Slam, além da oralidade e da musicalidade de ambos os estilos.

Nacionalmente, destacamos o repente brasileiro como gênero precedente e conectado ao Slam, por, desde a sua origem, partilhar da situação marginal, tanto em relação aos centros urbanos quanto aos eventos culturais elitizados na sociedade. Contendo elemento rítmico, performance oral, acompanhamento de instrumentos musicais e parcerias entre repentistas, sabemos que

Baseada em pressupostos da tradição, a cantoria nordestina desenvolveu-se, no Nordeste, como uma expressão marginalizada. Em princípio, produzida por indivíduos depreciados pela sociedade, a cantoria acontecia basicamente no meio rural, em sítios, fazendas, e não parecia 'elegante' gostar desse gênero, uma vez que era elaborada e direcionada a um grupo minoritário (SILVA, 2008, p. 14).

Novamente, emerge a situação das minorias que, em nosso trabalho, não é considerada em números, mas em desvantagem social, frente aos discursos e privilégios das classes dominantes. Assim como o Slam e o rap, o repente nasceu como expressão da cultura marginalizada, porém, proveniente do meio rural do Nordeste Brasileiro.

Essas aproximações revelam que a expressão artística e popular marginalizada ainda se manifesta, batendo na tecla da desigualdade, por meio do ritmo, da musicalidade e da oralidade performática, apresentando temas críticos e denunciativos em diferentes tempos e lugares. A partir de tal noção, entendemos que o Slam trata com o ritmo dos poemas os temas relevantes e vivenciados pelas pessoas que advêm da periferia ou se identificam com as problemáticas da periferia.

Em se tratando do universo lírico, é também o ritmo que determina a veloci- 
dade das informações e dos sentimentos apresentados nos poemas. É a própria percussão da poesia e

Nessa percussão, a imagem poética terá uma sonoridade do ser. O poeta fala no âmago do ser. Será necessário pois, para determinar o ser de uma imagem, senti-la em sua repercussão [...] (BACHELARD, 1989, p. 184).

O termo Slam, em tradução do inglês, significa algo como "batida", elemento que se aproxima do ritmo presente nas canções, nos versos de um poema, na contagem do tempo, nas fases da vida e da história. No Brasil, as batalhas de poesia são divididas em modalidades, como, por exemplo, "Slam Peleia", cuja temática é livre; "Slam do Trago", organizado sempre nos arredores de um bar, que exerce função de ponto de encontro dos participantes; "Slam Chamego", que tem por temática os poemas de amor; "Slam das Minas", com poemas de autoria feminina e que são declamados somente por mulheres; "Slam Ventre Livre", que trata das lutas das mulheres pela equidade de gêneros, pelo direito ao empoderamento e à autoafirmação em meio ao patriarcalismo; "Slam do gozo", no qual os temas dos poemas são ligados à sexualidade e ao erotismo; dentre outros que surgem ou se associam aos temas supracitados.

O Slam ocorre, em geral, nos espaços centrais, embora seja um movimento marginal, de acordo com as considerações antes explicitadas sobre o termo.
Isso porque, organizando-o no centro da urbe, as vozes oriundas da periferia são notadas e reverberam para além dos espaços de onde vêm. A localização centralizada, nessa ótica, demarca os problemas pelos quais os slammers passam, ou seja, promover uma edição de Slam no centro da cidade é uma forma de validar os posicionamentos defendidos nas suas performances. De outro ponto de vista, organizar o evento em um espaço central também funciona como facilitador de acesso para o público em geral, para novos poetas e para a propagação do evento.

Por se constituir em essência e estrutura como um movimento independente $\mathrm{e}$ autônomo, não é necessário que as pessoas mais familiarizadas com o Slam ou que sejam slammers há mais tempo autorizem a organização das batalhas, isto é, qualquer pessoa pode propor um evento, mesmo que outra edição aconteça simultaneamente. O que ocorre, comumente, é o fato de que as batalhas são agendadas e bastante divulgadas em redes sociais para que 0 público possa prestigiar e participar do maior número de Slams possível.

Portanto, para que o Slam aconteça, faz-se necessário que os poetas se inscrevam nas edições previamente divulgadas em páginas das redes sociais de acordo com a temática proposta. Isso significa que se o evento tratar, por exemplo, de temática feminista, como o "Slam das Minas" ou o "Slam Ventre Livre", nos 
quais ocorrem batalhas entre poetisas, apenas mulheres poderão se inscrever. Nas demais modalidades, as inscrições, que ocorrem no próprio local, são abertas a quaisquer poetas cujos poemas contemplem a temática sugerida pela edição.

Após as inscrições dos poetas, são indicados os jurados, nomeados entre voluntários do público que estiver presente, mediante a manifestação de interesse por tal função na dinâmica. A partir daí uma pessoa mediadora, geralmente a mesma que organizou o evento, dá início à batalha, proferindo um grito de guerra que identifique a temática da edição do Slam. Esse grito de guerra é respondido pela plateia como forma de incentivar os slammers antes de cada declamação.

A performance dos slammers, costumeiramente, não pode ultrapassar o tempo máximo de três minutos por poema declamado, contando com dez segundos de tolerância. Caso ultrapasse, cada segundo de acréscimo implica perda de um décimo da nota atribuída pelos jurados. Entretanto, não são os jurados que indicam a ultrapassagem do tempo limite nem eles que fazem o desconto da nota. Para isso, é indicada uma outra pessoa, geralmente envolvida na organização da edição, que registra as notas atribuídas e os descontos, caso sejam necessários. Ao término das batalhas, essa pessoa revela a média das notas, apontando, assim, o slammer vencedor.
Essa forma de promover o destaque da poesia relaciona-se diretamente à democracia e à liberdade de expressão, especificamente, à expressão poética. A poesia que habita o espaço furtivo do Slam nada mais é do que a luta violentamente pacífica pela conquista de um espaço legítimo na sociedade, a fim de que a voz dos anônimos seja ouvida, porquanto "A poesia dos tempos modernos é [...] 'meio muda, meio articulada'. É força, é representação" (BOSI, 1977, p. 92).

\section{Eu sou a Revolta da Chibata: poesia}

A fim de detalharmos nossa análise, cabe elucidar que a performance selecionada para análise foi registrada em vídeo e está disponível na internet, tanto na plataforma de vídeos do Youtube quanto em redes sociais, como o Facebook. Tal disponibilidade na rede virtual desvela grande parte da intenção de visibilidade e alcance referentes ao conteúdo de sua apresentação e à dinâmica do evento como um todo.

O poema Eu sou a Revolta da Chibata foi recitado na $26^{\mathrm{a}}$ edição do "Slam das Minas RS”, em Porto Alegre, e oportunizou à slammer, Natália Pagot (2019), uma vaga na edição "Slam Conexões", na qual só competem os vencedores de outras edições. A seguir, o poema, na íntegra: 
Aperta o calo que incomoda

A sobremesa indigesta dessa branca festa

Cheia de sorrisos falsos e falsas modéstias

A etiqueta da tua mesa não reinventa essa moda de escravizar as minas pretas

Não sustenta 500 anos de treta da preta que mega desenvolveu

Saiu do subemprego e na faculdade se meteu

Eu tô cagando pro padrão que é no Romeu

Eu só amo e morro pelos meus

E nem tenta me tirar da festa, meto um tiro de letra na tua testa

Lembra de mim? Aquela que na escola fez questão de não ver?

Fica esperta, eu tô sambando na tua cara

Repete agora 'Quem é a mulata?'

Eu não era, mas agora eu tô armada, nem raba, nem tapa

Te joguei no ringue foi com rima.

Baixei tua guarda, cuspi na tua lata

E não me chama de 'parsa'.

Segue aí, 'menina-barbie'

Só enfeita, enquanto a gente denuncia a barbárie

De quem precisa se esconder embaixo da mesa

Pra não levar tiro de escopeta.

Viemos botar o pé preto na porta, trouxemos a torta

Pig Minny Jackson ${ }^{3}$, ao som do Michael Jackson

Histórias Cruzadas e balas perdidas

Balas cruzadas e vidas perdidas

Histórias perdidas, balas certeiras

Eu sei, pra muitos não importa

Quero saber se a polícia chega com óbitos na sua porta

O nosso sangue pulsa, veia aorta

E não vejo a hora que acabe essa farra fardada

De melanina alvejada, algemada

Escorre o nosso sangue

Mães, gritos, violência, resiliência

Lágrimas jorradas

Triplas jornadas

Segue sendo coisa de preto

Invisibilizada.

Com vocês é preciso ver pra crer, né?

Então eu venho aqui acabar com essa festa entojada

Eu tenho poesia e granada

Eu sou a Revolta da Chibata

E minha rima será lançada

Quebrando todas as taças

E na hora do brinde, eu subo no palco

Desmascaro as verdades

Pisei no seu calo? Meus passos vêm de longe

Eu tenho quem me ouve

Poetas vivos, tome (PAGOT, 2019). 
O início do poema Eu sou a Revolta da Chibata é marcado pela consciência do eu lírico quanto ao incômodo que causa a sua presença e, mais especificamente, a presença de uma mulher negra, no local a que se refere. De imediato, percebemos uma crítica quanto às relações de dominação econômica exemplificada pelos versos "A etiqueta da tua mesa não reinventa essa moda de escravizar as minas pretas" (PAGOT, 2019). O excerto sugere um ambiente abastado e de socialização onde mulheres brancas sentem-se bem em ser servidas por mulheres negras.

O poema de Pagot e a sua condição de autora, mulher e negra legitimam o discurso denunciativo por meio de outros versos empoderados, ao mesmo tempo em que é-nos apresentada a diferença socioeconômica existente entre mulheres brancas e mulheres negras pela voz do eu lírico. Cabe ressaltarmos que, em $E u$ sou a Revolta da Chibata, o eu lírico está conectado à identidade da autora que se expressa por meio de uma performance. Nesse sentido, os versos da slammer contrapõem as barreiras históricas e destacam a situação de desigualdade, como no trecho em que é dito que a mesma etiqueta "Não sustenta 500 anos de treta da preta que mega desenvolveu/ Saiu do subemprego e na faculdade se meteu" (PAGOT, 2019).

Além da autoafirmação, percebemos que a linguagem utilizada no poema é lírica e, ao mesmo tempo, agressiva, pois coloca a poesia como arma contra as múltiplas formas de opressão. Assim depreendemos durante a leitura dos seguintes versos:

E nem tenta me tirar da festa/meto tiro de letra na tua testa/ [...] Eu não era, mas agora eu tô armada, nem raba, nem tapa/ Te joguei no ringue foi com rima./ Baixei tua guarda, cuspi na tua lata (PAGOT, 2019).

Além do caráter incisivo da linguagem utilizada, fica em evidência a crítica contra a objetificação sexual do corpo da mulher negra.

Notamos que, por meio da linguagem incisiva, é instaurada uma atmosfera de revanche contra ações de exclusão das mulheres negras dos processos sociais. $\mathrm{O}$ caráter de apropriação da cidadania, que também é sua, mas que lhe foi negada, de acordo com Pagot (2019), durante os quinhentos anos de sobrevivência, manifesta o critério sobre a afirmação da historicidade das mulheres negras escravizadas no Brasil.

Eu sou a Revolta da Chibata denuncia os privilégios das mulheres brancas legitimados pelo eurocentrismo difundido na Modernidade. O trecho "Segue aí, 'menina-barbie'/ Só enfeita, enquanto a gente denuncia a barbárie" (PAGOT, 2019) refere-se à passividade e despreocupação com a sobrevivência por parte das mulheres adequadas aos moldes eurocêntricos.

Junto à crítica aos privilégios das mulheres brancas sobre as mulheres negras, é explicitado o tom autoafirmativo da 
identidade étnica da slammer expresso pela subjetivação do eu lírico. Os versos "Eu tô cagando pro padrão que é no Romeu/ Eu só amo e morro pelos meus" (PAGOT, 2019) fazem referência ao padrão eurocêntrico e, para exemplificá-lo, a poeta menciona um personagem clássico de Shakespeare, autor clássico inglês.

Na sequência do poema, percebemos que a polifonia emerge e funciona como elemento-chave na construção de sentido em relação a outros fatos históricos e sociais ligados às situações expressas por Natália Pagot. Um exemplo que comprova a reverberação de outras vozes a partir da subjetivação do eu lírico e da condição étnica da slammer está no verso em que firma "Eu sou a revolta da chibata" (PAGOT, 2019).

Ao retomarmos a ideia de que, no contexto do poema, a poesia é tratada como arma e instrumento de denúncia contra a situação de desigualdade e silenciamento, a afirmação contida no verso estabelece relação direta com a Revolta da Chibata, ocorrida em 1910. A polifonia, além de rememorar as vozes dos que sofreram ou se engajaram com a Revolta da Chibata, evoca, nos versos de Pagot, a situação de subalternização das mulheres negras no âmbito do trabalho e nos processos de violência, por meio da naturalização do espaço marginal ocupado por elas em relação aos centros de dominação. A esse respeito, a slammer afirma que
Escorre o nosso sangue/ Mães, gritos, violência, resiliência/ Lágrimas jorradas/ Triplas jornadas/ Segue sendo coisa de preto/ Invisibilizada (PAGOT, 2019).

A utilização da $2^{\mathrm{a}}$ pessoa do plural para se referir à situação de subalternização realça o fenômeno polifônico preconizado por Bakhtin (1981), no que tange à reativação de diferentes vozes, isto é, o pronome "nosso" evoca as vozes de outras mulheres negras que partilharam ou partilham dos sentimentos expostos pela crítica da slammer.

Paralelamente à polifonia e aos tópicos anteriores, o poema evidencia a afirmação da marginalização de determinado grupo social e a problemática de gênero. Ambos são impressos no decorrer dos versos, que deixam claro o sentimento de não serem bem-vindas as mulheres negras no espaço onde o eu lírico do poema de Pagot as situa.

Todavia, esse espaço é descrito, também, como um lugar de resistência, onde os marginalizados decidem, consoante Pagot (2019), colocar o pé preto na porta. A metáfora sugerida pelo poema traz, envolta por uma essência conotativa, a noção de que as mulheres negras e mantidas à margem forçarão a sua entrada nos espaços sociais onde, até então, eram proibidas de circular.

Em resposta aos ataques racistas sofridos desde a época escolar, uma atitude de quem afronta a opressão é declarada pelo eu lírico, ligado à representatividade de Pagot para mulheres negras. Tal 
expressão pode ser observada nos versos "Lembra de mim? Aquela que na escola fez questão de não ver?/ Fica esperta, eu tô sambando na tua cara/ Repete agora 'Quem é a mulata?'” (PAGOT, 2019). A invisibilização exposta no excerto configura, com base nos pressupostos de Bourdieu (2012), uma forma de manifestação da violência simbólica que resultou no silenciamento histórico dos negros. Por outro lado, o enfrentamento proposto pela slammer demonstra a ocupação do lugar de fala, consoante Ribeiro (2017) e do lugar político, segundo Rancière (2005) retomada pelos grupos marginalizados.

A partir dos trechos destacados, é possível depreendermos o resgate da valorização quanto à história dos antepassados, pois são as lutas iniciadas no período do colonialismo brasileiro que justificam as denúncias e as ações de empoderamento feitas no presente e exemplificadas no poema de Natália Pagot (2019).

\section{Eu sou a Revolta da Chibata: a performance}

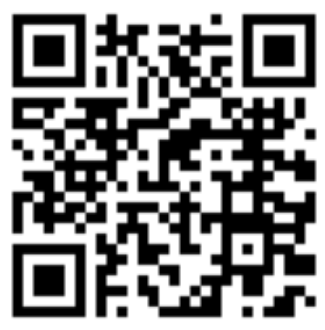

A poesia, parafraseando Zumthor (2014), é rítmica como a vida. Portanto, negar o potencial da oralidade na poesia é como negar o potencial de autoria e enunciação. Nesse sentido, é preciso destacarmos não somente os elementos estruturais de um poema de denúncia apresentado em uma edição do Slam, mas, também, a força da oralidade performática do slammer que participa da batalha de poesia.

Para além da apresentação dos slammers, também a função do público se faz necessária às performances que compõem as edições de Slam, pois são os receptores diretos da poesia produzida e interpretada. Ao passo que o poeta interage com a plateia, de acordo com Zumthor (2014), principia-se uma atmosfera poética advinda de uma união laica entre poeta e interlocutor que, juntos, descobrem, a cada performance, um mistério primitivo e sacral.

Admitindo-se a atualização da atmosfera poética em cada manifestação da subjetividade, individual ou coletiva, entendemos que cada situação de criação poética instaura uma nova e única forma de competência performática, uma vez que

\begin{abstract}
A performance se situa num contexto ao mesmo tempo cultural e situacional: nesse contexto ela aparece como uma 'emergência', um fenômeno que sai desse contexto ao mesmo tempo em que nele encontra lugar. Algo se criou, atingiu a plenitude e, assim, ultrapassa o curso comum dos acontecimentos (ZUMTHOR, 2014, p. 35).
\end{abstract}

É, pois, a reativação do fenômeno poético que mantém viva a poesia em 
instalações artísticas, em exposições de arte e, retomando nosso objeto de análise, em edições do Slam. Conforme o autor afirma, a performance que se instala e, ao mesmo tempo, migra do contexto cultural transcende à vivência comum dos fatos para se tornar a própria marcação destes. É devido a essa característica que inferimos ser a performance um dos mais significativos elementos constituintes da batalha de poesia. A performance evidencia o poema, mas, sobretudo, a voz e o corpo em movimento dos sujeitos envolvidos na dinâmica, ou seja, conforme Schechner (2006), uma performance ocorre por meio do conjunto de ação, interação e relação.

Durante a declamação performática, o slammer posta-se no centro de um círculo de pessoas que participam de sua apresentação entre um verso e outro de maior impacto. Emana do slammer a essência poética que emociona, diverte, provoca ou sensibiliza a plateia. Nesse sentido, consideramos que a sua performance “[...] é uma conduta na qual o sujeito assume aberta e funcionalmente a responsabilidade (ZUMTHOR, 2014, p. 35).

Nesse sentido, ao assistirmos à performance da slammer, podemos depreender que a poeta evidenciou a expressão humanizadora da literatura e colocou a sua própria materialidade viva a serviço dela. Isso é perceptível em vários pontos da performance, como no momento em que ela proferiu "A etiqueta da tua mesa não reinventa essa moda de escravizar as minas pretas" (PAGOT, 2019) e bateu no peito, indicando que também se identifica com o sofrimento de mulheres negras que foram escravizadas e cuja desumana condição era aceitável socialmente. $\mathrm{O}$ gesto de bater no peito é repetido no verso "O nosso sangue pulsa, veia aorta” (PAGOT, 2019), para destacar que, embora as mortes de negros sejam tantas e que, por isso, não causem espanto, essas pessoas não são apenas números, mas indivíduos com histórias, sentimentos, necessidades e vivências.

Ao afirmar "Eu tô cagando para o padrão que é no Romeu/ Eu só amo e morro pelos meus" (PAGOT, 2019), a slammer indica a inconformidade em relação ao jugo do padrão eurocêntrico, se curva e, com a mão fechada sobre o peito, demonstra afeto e irmandade para com outras pessoas negras.

Durante a performance, a poeta se opõe à desigualdade étnica, evidenciando não aceitar no presente as expressões de racismo vivenciadas no passado. A sua gestualidade acompanha essa oposição a partir, por exemplo, do dedo indicador em riste para seu interlocutor e o giro do corpo seguido da posição dos braços abertos para proferir "Fica esperta, eu tô sambando na tua cara/ Repete agora 'Quem é a mulata?'” (PAGOT, 2019).

Conforme explanado nos capítulos anteriores, o ritmo e a sonoridade são elementos próprios da poesia e, em $E u$ 
sou a Revolta da Chibata, o ritmo da performance de Natália Pagot fica acelerado no momento em que ela recita os versos "Histórias cruzadas e balas perdidas/ Balas cruzadas e vidas perdidas/ Histórias perdidas e balas certeiras" (PAGOT, 2019).

A aceleração nesse ponto da performance intensifica o contexto de mortes de pessoas negras ocasionadas por bala perdida. Além de tal inferência, é possível estabelecermos relação com o ritmo frenético dos batimentos cardíacos de quem passa por essa situação de adrenalina, pois os versos supracitados são precedidos pela denúncia contra a circunstância indigna dos que têm de se esconder para não serem atingidos por tiros de escopeta.

Cabe destacarmos que a última palavra do excerto ("certeiras") é pronunciada após uma breve pausa, o que aponta, apoiado nas pressuposições sobre a aceleração da performance, para o fim do momento de adrenalina e à suspensão dos batimentos cardíacos. Agestualidade da slammer condiz com essa interpretação, uma vez que finaliza o verso com a mão simbolizando uma arma na lateral da cabeça.

Por meio da voz de Natália Pagot, a polifonia ganha destaque, pois na sua performance reverberam as vozes dos que sofreram com a escravidão, reativa-se o discurso de contestação das mulheres objetificadas sexualmente e dos que vivem em lugares onde as mortes por bala perdida configuram a rotina de uma realidade violenta.

De forma semelhante, a função catártica se ajusta nas vozes dos que presenciaram a apresentação ao vivo e participaram dela, desde o grito de abertura da performance que é iniciado pelo mediador das batalhas ("Poesia contamina!") e respondido pela plateia ("Slam" das minas!") até manifestações de apoio ou admiração por algum trecho impactante. A exemplo de interjeições de admiração, temos a resposta do público aos versos nos quais a poeta faz referência a uma importante personagem fílmica e ao cantor e ícone do Pop dos anos 1980. Ao declamar "Viemos botar o pé preto na porta, trouxemos a torta/ Pig Minny Jackson ao som do Michael Jackson" (PAGOT, 2019) algumas vozes da plateia sussurram "Nossa!", demonstrando sua impressão sobre o teor crítico e representativo da performance da slammer.

A partir da identificação do público com o conteúdo crítico, denunciativo e, por vezes, agressivo, depreendemos que a catarse é projetada por meio da participação dessas pessoas na apresentação da poeta. No verso em que ocorre a aceleração da fala de Natália Pagot, a última palavra, "certeiras" (2019), também é pronunciada pelo público. Tal fenômeno pode indicar que o excerto do poema, apresentado em outra edição, causou tamanha perturbação que foi rememorado pelo público participante da 
edição de Slam em que a performance foi registrada. Nessa perspectiva, depreende-se outra face do processo polifônico, visto que, pela partilha do verso entre poeta e público, ocorre a reativação das vozes dos que já ouviram o poema e com ele se comovem.

$\mathrm{O}$ atravessamento das vozes da plateia com a voz da slammer constrói uma teia de sentidos a quem assiste ao vivo pela primeira vez a uma apresentação na dinâmica do Slam e às pessoas que assistem à performance no Youtube, devido ao fato de unidas evidenciarem o caráter politizado dos debates e questionamentos propostos com base no que os slammers chamam de Terrorismo Lírico.

Não obstante, afirmamos que assistir à gravação de um Slam difere muito de participar ao vivo de uma edição, posto que, ao vivo, é possível que o sujeito se envolva com a essência do poema, partilhe do caráter humanizador do evento e utilize a sua própria voz a fim de contribuir para com as performances que batalham juntas pela visibilidade das lutas das minorias políticas e o protagonismo de quem ocupa o seu lugar de fala a cada verso declamado.

O cenário para a $26^{a}$ edição do "Slam das Minas" foi a Praça da Matriz em Porto Alegre e as informações postadas abaixo da identificação do vídeo confirmam esse espaço público como palco aberto de todas as edições da referida modalidade de batalha de poesia. Com base nisso, percebemos a preferência por locais públicos e com bastante visibilidade social para a organização das batalhas. Trata-se da ocupação de espaços públicos de cidadania, uma vez que tais espaços não costumavam receber intervenções artísticas organizadas e protagonizadas pelas pessoas cujas vozes foram, durante muito tempo, silenciadas.

Por fim, destacamos a temática do poema, que abordou prioritariamente questões de gênero e etnia como elementos-chave para o último critério proposto: a demarcação do lugar de fala. É preciso salientarmos que a slammer Natália Pagot é uma mulher negra e, ainda que uma mulher branca ou um homem negro se unam às causas contra o racismo ou a favor do feminismo, por exemplo, cada um terá o seu lugar de fala sobre o tema.

Em outras palavras, uma mulher branca não experimentará o racismo da mesma forma que uma mulher negra ou indígena, tampouco, o peso de manifestações de racismo contra mulheres brancas se equipara à carga histórica contida em práticas racistas contra mulheres negras ou indígenas, mesmo que contra ele ambas lutem em princípios e atitudes. $\mathrm{O}$ mesmo ocorre em relação a homens e mulheres que se associam à bandeira de igualdade difundida pelo movimento feminista e em relação às pessoas que se adequam à cisgeneridade, mas que se identificam com as agendas da comunidade LGBTQ. 


\section{Considerações finais}

A literatura torna possível a invenção de um futuro mais humano, a partir da premissa de que

O homem é um animal político porque é um animal literário, que se deixa desviar de sua destinação "natural" pelo poder das palavras (RANCIÈRE, 2005, p. 59-60).

Esse poder da palavra tem representação dual na sociedade, porquanto pode ser instrumento valioso de emancipação dos sujeitos, como também pode ser distorcido a favor das narrativas dominantes.

Partindo da premissa de que a literatura é um direito de todos, propor reflexões torna-se necessário também quando percebidas restrições a seu acesso e universalização. Entender o fenômeno artístico é entender a necessidade que cada sujeito tem de se colocar como narrador de sua história, de centralizar sua enunciação. Dessa forma, acreditamos ser pela linguagem que nos movimentamos como fenômeno humano para compreender a memória social e sua significação na ordem artística do sujeito. É, portanto, a palavra enunciada que carrega em si uma rede de significação, a qual centraliza e marginaliza culturas constituintes da mesma ossatura antropológica.

Ao debruçarmo-nos sobre os estudos do Slam, encontramos o modo como as batalhas propiciam um novo espaço de produção e partilha poética, podendo abrir caminhos para descobertas no âmbito da autoafirmação e do reconhecimento a respeito das múltiplas lutas pela conquista de espaço. Essas lutas foram iniciadas no passado, mas precisam ser ressignificadas no presente, a fim de que as gerações futuras possam conhecer uma nova forma de sociedade em que mulheres e homens, crianças, idosos e jovens, com suas etnias e sexualidades, tenham seus direitos validados e preservados com equidade e dignidade.

O Slam, nesse sentido, desempenha papel fundamental à valorização e ao desvelamento de vozes historicamente estabilizadas à margem da sociedade. $\mathrm{E}$ mais, cumpre dois papéis na ordem do sistema literário: relê e, por isso, renova, pela poesia, a oficialidade histórica e concede voz àqueles a quem a história reservou a afonia.

\section{Slam: poetry and endurance performance}

\section{Abstract}

this paper aims to show how the Slam provides a new space for production and poetic sharing, and may open the way for discoveries in the context of self-affirmation and recognition on the multiple struggles for the conquest of space, raising voices historically relegated to the borders of social life. It presents a dialogical and polyphonic analytical look, as well as Paul Zumthor's understanding of performance; and it presents the case of 
Natália Pagot, a slammer who stands out for her poetic and performance. The work also points out the idea of sharing the sensitive of Jacques Rancière, from which he defends the idea of freedom from imaginary conditions so that future generations are able to know a new form of society where women and men, children, older and young people, with their ethnicities and sexualities, have their rights validated and preserved with fairness and dignity.

Keywords: Slam; Voices; Performance; Polyphony

\section{Notas}

1 O Ato Institucional número 5 foi o $5^{\text {o }}$ decreto emitido pelo governo militar brasileiro e entrou em vigor em 13 de dezembro de 1968. É considerado o golpe mais severo na democracia e deu poderes quase absolutos ao regime civil-militar (CARVALHO, 2018).

2 Cronotopo, conforme elabora Machado (2005), é o elemento que trata das conexões essenciais das relações de tempo e espaço, assimiladas de forma artística na literatura, pois os gêneros, de acordo com o dialogismo, fazem parte da cultura, na qual se manifestam na forma de "memória criativa", onde circulam as descobertas e ações significativas do ser humano no tempo e no espaço.

3 Minny Jackson é uma personagem negra do filme estadunidense Histórias Cruzadas (The Help) baseado na obra literária homônima de Kathryn Stokett, que ambientou a narrativa na cidade de Jackson, capital do Mississipi. Em decorrência de sua demissão, Minny resolve presentear a ex-patroa que a demitiu por racismo com uma torta cuja receita continha fezes. A cena da degustação representa a libertação de tantos maus tratos e subalternização sofridos por Jackson.

4 A câmera do smarthfone deve focar o $Q R$ Code para que o vídeo abra no navegador ou no aplicativo do Youtube.

\section{Referências}

BACHELARD, Gaston. A Poética do espaço. São Paulo: Martins Fontes, 1989.

BAKHTIN, Mikhail. Problemas da poética de Dostoiévski, Rio de Janeiro: Ed. ForenseUniversitária, 1981.

BEZERRA, Paulo (org.). Os gêneros do discurso. São Paulo: Editora 34, 2006.

BOSI, Alfredo. O ser e o tempo da Poesia. São Paulo: Cultrix, 1977.

BRITTO, Clovis Carvalho. Mulheres nos interstícios de uma "geração mimeógrafo": itinerários de Ana Cristina César. Revista Eletrônica Literatura e Autoritarismo Dossiê, Maio de 2012 - ISSN 1679-849X. Disponível em: http://w3.ufsm.br/grpesqla/ revista/dossie07/RevLitAut_art05.pdf . Acesso em: 30 mai. 2018.

CANDIDO, Antonio. O direito à literatura. In: Vários escritos. 4. ed. São Paulo: Duas Cidades, 2004.

CARVALHO, Talita de. Ditadura Militar no Brasil. Disponível em: https://www.politize. com.br/ditadura-militar-no-brasil/ . Acesso em: 20 out. 2018.

COMPAGNON, Antoine. O Demônio da Teoria: literatura e senso comum. Belo Horizonte: Ed. UFMG, 1999.

CUNHA, Helena P. Os gêneros literários. In: PORTELLA, E. et. al. Teoria Literária. Rio de Janeiro: Tempo Brasileiro, 1979, p. 93-130.

COMPAGNON, Antoine. O Demônio da Teoria: literatura e senso comum. Belo Horizonte: Ed. UFMG, 1999.

COSTA, Joaze Bernardino; GROSFOGUEL, Ramón. Decolonialidade e perspectiva negra. Revista Sociedade e Estado - Vol. 31. Número 1 Janeiro/Abril 2016. Disponível em: http://www.scielo.br/pdf/se/v31n1/0102-6992se-31-01-00015.pdf. Acesso em: 25 maio 2019. 
CUNHA, Helena P. Os gêneros literários. In: PORTELLA, E. et. al. Teoria Literária. Rio de Janeiro: Tempo Brasileiro, 1979, p. 93-130.

ECO, Umberto. Sobre a literatura. Rio de Janeiro: BestBolso, 2011.

ESTEVES, Laurenci Barros; MENDES, Renata Rodrigues. Características das Cantigas de Escárnio Presentes no Rap "Fala Sério", de Gabriel, "O Pensador”. São Paulo: Revista Anagrama. Revista Científica Interdisciplinar da Graduação. Ano 4 - Edição 3 - Mar. - Mai. 2011.

GOLDSTEIN, Norma. Versos, sons ritmos. 13. ed. São Paulo: Ática, 2005.

LAJOLO, Marisa. O que é Literatura? 2. ed. São Paulo: Brasiliense, 1982.

MACHADO, Irene. Gêneros Discursivos. In: Bakhtin: Conceitos-chave. BRAIT, BETH et al. (org.). São Paulo: Contexto, 2005.

MATTOSO, Glauco. O que é Poesia Marginal. 2. ed. São Paulo: Editora Brasiliense, 1981.

PAGOT, Natália. Eu sou a Revolta da Chibata. Slam das Minas. Porto Alegre, 2019. 2min. 33s. Disponível em: https://www.youtube.com/watch?v=I4bD1eV0l-A . Acesso em: 29 maio 2019.

RANCIÈRE, Jacques. A partilha do sensível: Estética e política. São Paulo: EXO, 2005.

RIBEIRO, Djamila. O que é lugar de fala? Belo Horizonte: Letramento, 2017.

ROMAN, Artur Roberto. Conceito de polifonia em Bakhtin - O trajeto polifónico de uma Metáfora. Letras, n.41-42, p. 195-205. Curitiba, UFPR, 1993. Disponível em: https://revistas.ufpr.br/letras/article/download/19126/12426 . Acesso em: 29 mai. 2018.

SCHECHNER, Richard. What is performance? In: Performance Studies: an Introduction, second edition. Nova Iorque \& Londres: Routledge, p. 28-51. Disponível em: https:/ppgipc.cienciassociais.ufg.br/ up/378/o/O_QUE_EH_PERF_SCHECHNER. pdf . Acesso em: 21 abr. 2019.
SILVA, Andréa Betânia da. A constituição do ethos e da cenografia nos festivais do circuito baiano da viola. Dissertação de Mestrado - Instituto de Letras. Universidade Federal da Bahia - Salvador/BA, 2008. Disponível em: https://repositorio.ufba.br/ ri/bitstream/ri/12036/1/Andr\%c3\%a9a\%20 Bet\%c3\%a2nia\%20da\%20Silva.pdf. Acesso em: 06 out. 2019.

WELLEK, René; WARREN, Austin. Teoria da literatura e metodologia dos estudos literários. São Paulo: Martins Fontes, 2003.

ZUMTHOR, Paul. Performance, recepção, leitura. São Paulo: Cosac Naify, 2014. 